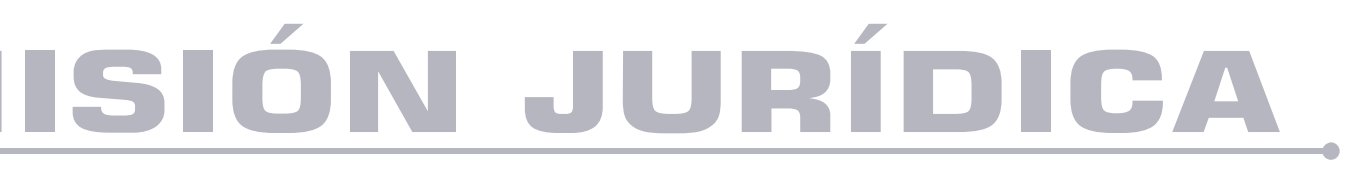

\title{
Aproximaciones a la migración colombovenezolana: desigualdad, prejuicio y vulnerabilidad
}

Approach to the Colombian-Venezuelan migration: inequality, prejudice and vulnerability

Autores: Esther Pineda, Keymer Ávila

DOI: https://doi.org/10.25058/1794600X.988

\footnotetext{
SP MISIÓN JURÍDICA A 


\section{APROXIMACIONES A LA MIGRACIÓN COLOMBO-VENEZOLANA: DESIGUALDAD, PREJUICIO Y VULNERABILIDAD*}

\author{
APPROACH TO THE COLOMBIAN- \\ VENEZUELAN MIGRATION: INEQUALITY, \\ PREJUDICE AND VULNERABILITY \\ ABORDAGENS À MIGRAÇÃO COLOMBO- \\ VENEZUELANA: DESIGUALDADE, \\ PRECONCEITO E VULNERABILIDADE
}

\section{RESUMEN}

La situación política, económica y social de Colombia durante décadas motivó la migración de sus ciudadanos hacia el territorio venezolano, lo cual se acentuó con el conflicto armado. Venezuela, que se caracterizó desde los años 50 del siglo XX por ser un país receptor de inmigrantes, dejó de ser un destino atractivo a partir de los años 80 por la crisis económica y política que atravesó, época a partir de la cual pueden detectarse las primeras oleadas de migrantes venezolanos. Pero es a partir del año 2015 cuando se evidencia un incremento de este fenómeno como consecuencia de la profundización de la crisis política, económica y social experimentada por la sociedad venezolana y la pauperización de las condiciones de vida de gran parte de la población; esta situación ha

\footnotetext{
*Artículo de reflexión.

a. Socióloga (2010), Magíster Scientiarum en Estudios de la Mujer Mención Honorífica (2013), Doctora en Ciencias Sociales Mención Honorífica (2015) y Postdoctora en Ciencias Sociales egresada de la Universidad Central de Venezuela.

b. Abogado Magna cum Laude, egresado de la Universidad Central de Venezuela (UCV). Máster Oficial en Criminología y Sociología Jurídico Penal, Universitat de Barcelona (UB). Investigador del Instituto de Ciencias Penales, Profesor de Criminología en pre y postgrado de la UCV. Colaborador del Observatorio del Sistema Penal y los Derechos Humanos de la UB.
}

Esther Pineda G. ${ }^{\text {a }}$ estherpinedag@gmail.com Keymer Ávilab keymerguaicaipuro@gmail.com Fecha de recepción: marzo 12 de 2019 Fecha de revisión: marzo 29 de 2019 Fecha de aceptación: abril 03 de 2019

Para citar este artículo: Pineda, G., y Ávila, K. (2019) Aproximaciones a la migración colombovenezolana: desigualdad, prejuicio y vulnerabilidad. 
convertido a Colombia en la opción migratoria más cercana y accesible para los venezolanos en busca de oportunidades.

\section{PALABRAS CLAVE}

Crisis; Migración; Colombia; Venezuela.

\section{RESUMO}

A situação política, econômica e social da Colômbia durante décadas motivou a migração de seus cidadãos para o território venezuelano, que se acentuou com o conflito armado. A Venezuela, caracterizada desde os anos 50 como um país receptor de imigrantes, deixou de ser um destino atraente desde a década de 1980, devido à crise econômica e política pela qual passou; período em que as primeiras ondas de migrantes venezuelanos podem ser detectadas. Mas é a partir de 2015 que se evidência um aumento desse fenômeno em consequência do aprofundamento da crise política, econômica e social vivida pela sociedade venezuelana e do empobrecimento das condições de vida de grande parte da população. Essa situação tornou à Colômbia opção de imigração mais próxima e mais acessível para os venezuelanos em busca de oportunidades.

\section{PALAVRAS-CHAVE}

Crise; Migração; Colômbia; Venezuela

\section{ABSTRACT}

The political, economical and social situation of Colombia for decades caused the migration of its citizens towards Venezuelan territory, this was deepened by the armed conflict. Venezuela was characterized since the fifties as being a country that received immigrants, but ceased to be an attractive destination from the eighties because of the economical and political crisis that the country passed through, a time from which the first waves of Venezuelan migrants can be recognized. However it is from the year 2015 when a growth of this phenomenon is evidenced as a consequence of the deepening of the political, economical and social crisis that Venezuelan society was going through, leading to an impoverishment of life conditions of a large proportion of the population, a situation that has turned Colombia into the nearest and most accesible migratory option for Venezuelans looking for better opportunities.

\section{KEYWORDS}

Crisis, Migration, Colombia, Venezuela.

\section{INTRODUCCIÓN}

Desde el año 2015 los migrantes venezolanos han ocupado lugares importantes en los medios de comunicación y en la agenda política internacional. Por tierra, mar y aire se desplazan en busca de mejores condiciones de vida. Algunos emprenden riesgosas y extensas caminatas por rutas que pueden alcanzar 3.500 kilómetros, otros arriesgan sus vidas en el mar, y muchos de ellos pernoctan en las calles; situación que ha profundizado los prejuicios y estereotipos con respecto a los migrantes venezolanos, con énfasis en aquellos más depauperados.

Como respuesta a esta intempestiva movilidad intrarregional de venezolanos, Colombia solicita ayuda económica para atenderlos, Perú declara estado de emergencia sanitaria en la frontera y Brasil moviliza sus tropas. La Agencia de la Organización de Naciones Unidas (ONU) para los Refugiados (ACNUR) y la Organización Internacional para las Migraciones (OIM) han manifestado sus preocupaciones sobre el incremento reciente de esta movilización de personas y han publicado durante 2018 diversas cifras que lo evidencian. No obstante, Colombia al ser el país vecino con mayor cercanía tanto física como cultural y ofrecer rutas más accesibles, es el destino que se ha visto más afectado por esta situación.

Los venezolanos en territorio colombiano ya superan el millón de migrantes. Al menos la mitad se encuentra en condición regular, el $60 \%$ oscila entre los 18 y 39 años de edad y, se concentran principalmente en Bogotá y otras regiones fronterizas. Destacan como su mayor motivación para migrar la búsqueda de empleo, fuentes de subsistencia y el envío de remesas. Al menos un $40 \%$ tiene doble nacionalidad y otro $30 \%$ son colombianos. Sin embargo, el proceso migratorio es experimentado de forma diferenciada, generizada y sexualizada por las mujeres venezolanas, quienes se enfrentan a los prejuicios y estereotipos de género, así como, a los riesgos de la prostitución, la trata de personas y el femicidio/feminicidio. En este contexto la recepción de migrantes se ha convertido en un reto, especialmente en términos de políticas públicas. 


\section{Aproximaciones a la motivación de la migración extra e intra regional en América Latina}

Una cantidad importante de migrantes internacionales ${ }^{1}$ tienen como motivación la aspiración personal y familiar, la búsqueda de oportunidades de crecimiento académico y laboral, la prosperidad económica, así como, la afinidad y el interés por la diversidad cultural, la realidad es que estos no son la mayoría; las grandes proporciones de migrantes del mundo abandonan sus tierras como consecuencia de desastres naturales, procesos bélicos, altos niveles de conflictividad política y social, violencia, persecuciones, masacres, violación de los derechos humanos, incertidumbre e inestabilidad económica y social, desigualdad, la pauperización de la vida, la enfermedad, la pobreza crítica y el hambre colectiva.

Estas condiciones y motivaciones que impulsan al sujeto a la migración internacional, determinan también en muchos casos la forma en que lo hacen, es decir, de forma legal o irregular, permanente o temporal, progresiva o acelerada, particular o masiva. En el caso de América Latina las motivaciones para el ejercicio de la migración ha sido diversas, las dictaduras experimentadas en el cono sur y en los países centroamericanos, así como, la violencia generalizada determinaron un tipo de migración; sin embargo, esta se caracterizó por ser una migración extra-regional pues en América Latina y El Caribe fue poco frecuente la migración intra-regional, con excepción del conflicto armado en Colombia que propició uno de los movimientos intra-regionales más grandes y prolongado de la región.

Una característica fundamental de la región de América Latina y el Caribe es la migración hacia América del Norte. En 2015, aproximadamente 25 millones de migrantes habían emprendido la travesía hacia el norte y residían en América del Norte. La población de América Latina y el Caribe que vive en América del Norte ha aumentado de manera

1. Las Recomendaciones sobre estadísticas de las migraciones internacionales de las Naciones Unidas (1999) definen al migrante internacional como cualquier persona que ha cambiado su país de residencia habitual y distinguen entre "migrante por breve plazo" (aquel que ha cambiado su país de residencia habitual durante al menos tres meses, pero no durante un plazo superior a un año) y "migrante por largo plazo" (aquel que lo ha hecho durante al menos un año) considerable a lo largo del tiempo: se calcula que ha pasado de 10 millones en 1990 hasta casi 25 millones en 2015. Otros 4,6 millones se encontraban en Europa, un aumento respecto de los 1,1 millones de 1990. El número total de migrantes de otras regiones que vive en América Latina y el Caribe se ha mantenido relativamente estable, en torno a los 3 millones durante los últimos 25 años. Este grupo está formado principalmente por europeos (cuyo número disminuyó ligeramente durante el periodo mencionado) y norteamericanos (cuyo número aumentó) (...) La característica más llamativa de los principales corredores migratorios dentro y desde la región es el predominio de los Estados Unidos de América como principal país de destino. La mayoría de los corredores se dirigen hacia los Estados Unidos de América, mientras que el resto discurre dentro de la región (por ejemplo, de Colombia a la República Bolivariana de Venezuela) (OIM, 2018a: 84, 87).

Pese a ello, la migración en América Latina en el pasado y en la actualidad se ha caracterizado por tener motivaciones económicas, es decir, la mayoría de los migrantes provenientes de países con severas crisis económicas y escenarios de inestabilidad política, se movilizan en búsqueda de empleo y una mejor remuneración que les permita satisfacer sus necesidades y las de sus familias ante un deterioro de la condiciones de vida, dado que:

Los salarios que perciben los migrantes en el extranjero pueden superar con creces aquellos que obtendrían en empleos similares en sus países de origen. (...) Las diferencias de salario y el incremento relativo de los ingresos obtenidos de la migración son mayores entre los trabajadores menos cualificados, cuyo movimiento internacional en el mundo está más restringido. El aumento de los ingresos de los migrantes también puede dar lugar a mejoras considerables en el bienestar y el desarrollo humano de sus familias, ya sea directamente si residen junto con el migrante en el país de acogida, o indirectamente a través de remesas. Cabe señalar que los efectos positivos de la migración para los migrantes y sus familias trascienden el mero impacto económico y generalmente conllevan mejoras en otras dimensiones del desarrollo humano, como la educación y la salud (OIM, 2018a: 4). 
Este hecho como lo señalan Sandell, Sorroza y Olivié (2001), nos coloca ante una nueva era de la migración, donde el factor económico como causa de la salida de muchas personas de sus países de origen cobra primacía; no obstante, este fenómeno desencadena nuevas tensiones y problemáticas pues, como afirma Dávila (2001), los países de destino o receptores se muestran cada vez menos dispuestos a acoger a los trabajadores inmigrantes, situación que se expresa en la colocación de nuevos y mayores obstáculos burocráticos, pero también mediante el despliegue de cuerpos de seguridad en zonas fronterizas, el cierre de fronteras o el levantamiento de muros físicos que permitan frenar y desincentivar los flujos migratorios.

\section{La migración colombiana hacia Venezuela}

La situación política, económica y social de Colombia durante décadas motivó la migración de sus ciudadanos, la cual se profundizó y masificó con el conflicto armado; ante ello, desde los años 50 el principal destino de los colombianos fue el territorio venezolano, el cual según Álvarez (2004) funcionó como receptor de mano de obra colombiana calificada, no calificada y campesina; principalmente en zonas fronterizas por las relaciones de vecindad, permeabilidad de las fronteras y facilidades comunicacionales.

Señala Álvarez (2004) con base a los censos de población de Venezuela que, el número de colombianos residenciados entre los años 1951 a 1971 tuvo una variación significativa, pasando de 45.969 a 102.314; por su parte Gómez y Rengifo (1999) afirman que la población colombiana residente en Venezuela experimentó un incremento sustancial de 194\% entre 1970 y 1990. Este flujo migratorio en condición de regulares e irregulares, tuvo como fundamental motivación la búsqueda de oportunidades laborales, empero, encontraron limitaciones para su inserción en la economía venezolana; situación por la que los colombianos en el país tuvieron que desempeñarse en oficios de muy baja remuneración y baja calificación, destacando el trabajo agrícola, obrero, el transporte y el servicio doméstico.

Tras el desplome de la economía venezolana en la década de los 80 el país dejó de ser atractivo para los migrantes y comenzó a disminuir la intensidad del flujo de colombianos hacia Venezuela, evidenciándose incluso un proceso lento de retorno. Posteriormente el recrudecimiento del conflicto armado generó un cambio del patrón migratorio, por lo cual los colombianos pasaron de ser migrantes en búsqueda de oportunidades económicas y laborales, a colombianos solicitantes de asilo y refugio.

En el año 1999, a raíz del enfrentamiento entre los grupos guerrilleros colombianos y las Autodefensas en la región del Catatumbo -región colindante con Venezuela- se produjo el desplazamiento de más de 3 mil personas hacia la zona fronteriza venezolana. Es entonces cuando se percibe por primera vez la situación de refugiados colombianos en territorio venezolano, por motivaciones de índole de política interna colombiana (Álvarez, 2004: 198).

Esta situación de desplazamiento de la población se mantuvo durante décadas, según la Organización Internacional para las Migraciones (2018a) más de 7,2 millones de colombianos continuaban en situación de desplazamiento interno a finales de 2016; año en el cual Colombia fue el principal país de origen de refugiados en América Latina y el Caribe debido a su prolongado conflicto interno. La mayoría de los refugiados de Colombia fueron acogidos en los vecinos países de Venezuela y Ecuador, países en los que para 2015 se encontraban casi 1,2 millones de colombianos. Sin embargo, señalan la OIM (2018a) y Banco Mundial (2018) que las conversaciones de paz de finales de 2016 y 2017 que permitieron a Colombia dejar atrás cincuenta años de violencia, sumadas al agravamiento de la situación de inestabilidad económica, institucional y política que atraviesa Venezuela, han revertido la tendencia en los últimos años; creado las condiciones para el retorno de muchos colombianos a su país ${ }^{2}$ y convirtiendo a Colombia en el país del mundo que más venezolanos alberga actualmente.

\section{De receptores a expulsores: La caracterización de la migración venezolana}

Durante décadas Venezuela se caracterizó por ser un país receptor de inmigrantes ${ }^{3}$, quienes

2. En el año 2015 según Banco Mundial (2018) retornaron 22 mil colombianos desde Venezuela tras ser expulsados por el gobierno del vecino país; pero tras la agudización de la crisis, este organismo estima que para septiembre de 2018 habrían retornado más de 300 mil colombianos desde Venezuela.

3. Algunas de las ideas generales de esta sección tienen su origen en un breve artículo en el que se elaboraron unas primeras 
con base en el censo de población de 1960, llegaron a conformar el 15\% de los habitantes del país. En el imaginario colectivo nacional aún se tiene presente la política promovida por el dictador Pérez Jiménez, quién producto de la bonanza petrolera en la década del 50 intentó "modernizar" al país pero también de "blanquearlo", incentivando la inmigración de al menos 800.000 personas, muchas de ellas campesinos y trabajadores calificados de España, Italia y Portugal que huían empobrecidos después de la Segunda Guerra Mundial. Estas ideas como bien lo señala Ramos (2010) no eran una novedad, por el contrario, tenían sus antecedentes en el gobierno de López Contreras durante la segunda mitad de la década del 30. Pero esta política de puertas abiertas no fue para todos, mientras se incentivaba la inmigración europea, se estigmatizaba y obstaculizaba la inmigración de las personas provenientes en su mayoría de Colombia, Ecuador, Perú y las Antillas, que veían en Venezuela una tierra de oportunidades.

A partir del año 1973 con el boom petrolero aunado a las dictaduras del cono sur, se generó otra gran oleada de inmigrantes hacia Venezuela, en esta oportunidad suramericanos. Esta situación cambió con las sucesivas devaluaciones a partir de la abrupta caída del bolívar frente al dólar estadounidense sufrida el viernes 18 de febrero de 1983, y la crisis socioeconómica que devino en el Caracazo durante 1989, episodios que marcaron un quiebre político e institucional en el país. Tras estos eventos comienzan a detectarse las primeras oleadas de emigrantes venezolanos, los cuales según Barrios (2018) se caracterizaban por poseer un perfil profesional, así como, en muchos casos, por ser descendientes de los europeos llegados al país en la década del 50.

No obstante, en las últimas dos décadas algunos autores como Páez (2015) distinguen tres oleadas migratorias: 1) Entre los años 2002 y 2003 posterior al golpe de Estado contra el Presidente Hugo Chávez y el paro petrolero. 2) Entre 2006 y 2007 tras la primera reelección del Presidente Chávez. 3) Durante los últimos ocho años, la cual ha ido incrementándose especialmente a partir del año 2015. Las dos primeras constituidas por las capas medias y altas de la sociedad, principalmente empresarios y profesionales

reflexiones sobre la migración venezolana: A Venezuelan Exodus? (Avila, 2018a). que destacaban entre sus motivaciones para migrar la inseguridad ${ }^{4} \mathrm{y}$ el entorno político y social; estos generalmente partían con una planificación, con recursos y vía aérea hacia destinos como Estados Unidos, España y Panamá. La tercera se ha caracterizado por presentar un perfil más democratizado, abarcando a toda la estructura de la sociedad venezolana. En esta destaca particularmente la migración de personas pertenecientes a los sectores con menos recursos económicos y formación académica, lo cuales probablemente en otras condiciones no se habría planteado migrar.

A partir del año 2013 se agudiza en Venezuela una crisis institucional y política, que confluye con problemas de diversa naturaleza, el principal de ellos de carácter económico ${ }^{5}$; situación que redujo el disfrute de los derechos económicos, sociales y culturales (DESC) de la población. La caída del producto interno bruto $(\mathrm{PIB})^{6}$, la hiperinflación sin precedentes ${ }^{7}$, los altos índices de escasez de

4.En Venezuela según Ávila (2018b) se afrontan graves problemas en materia de seguridad ciudadana, con altas tasas de homicidios (62 por cada cien mil habitantes para 2017) y de violencia institucional (las muertes en manos de las fuerzas de seguridad abarcan el $26 \%$ de los homicidios en el país) que solo reproducen e incrementan un continuo ciclo de violencia estructural.

5. Esta recesión y reducción sostenida de la producción petrolera en Venezuela según Lander (2018) se inicia al menos tres años antes de las sanciones financieras impuestas por el gobierno de Donald Trump.

6. Según la CEPAL en su informe "Estudio Económico de América Latina y el Caribe 2018. Evolución de la inversión en América Latina y el Caribe: Hechos estilizados, determinantes y desafíos de política" publicado en el mes de octubre de 2018, se proyectaba una caída del $12 \%$ del PIB en la República Bolivariana de Venezuela, lo que supone cinco años consecutivos de contracción y una caída acumulada que supera el $40 \%$ respecto al nivel exhibido en 2013. Por su parte el Fondo Monetario Internacional calculó una caída del producto interno bruto en el orden de $18 \%$ durante 2018 lo cual significó una contracción económica de alrededor de 45\% desde 2013, atribuible al desplome de la producción de petróleo, la inestabilidad política y socia y distorsiones generalizadas a nivel microeconómico, que se suman a importantes desequilibrios macroeconómicos; y que, ante la ausencia de correctivos, se estima una contracción de 5\% para 2019.

7. Según la CEPAL durante 2017 la tasa de inflación anual superó el $2.500 \%$ y desde noviembre de ese año se registraron tasas de inflación mensuales superiores al 50\%, la cual es atribuida al crecimiento elevado de los agregados monetarios, el financiamiento de la gestión fiscal con los ingresos por emisión monetaria, la depreciación pronunciada del tipo de cambio, los aumentos salariales y la severa restricción para la obtención de divisas. Por su parte las estimaciones del Fondo Monetario Internacional (2018a) en su informe "Perspectivas económicas. Las Américas: Una Recuperación Despareja", da cuenta de que la inflación alcanzó $2.500 .000 \%$ para el cierre de 2018. Como se espera que continúe el financiamiento monetario de los abultados déficits fiscales y que la demanda de dinero siga desplomándose, la inflación se acelerará aún más, calculándose 
medicamentos $^{8}$, la escasez de alimentos y el alto costo de la canasta alimentaria familiar ${ }^{9}$, el aumento de la pobreza ${ }^{10}$ y la vertiginosa pauperización de las condiciones de vida, la pérdida de beneficios laborales, la pulverización de los salarios de la clase trabajadora, el desempleo ${ }^{11}$, las severas restricciones a la oferta laboral en el país (CEPAL 2018), la desaparición de la capacidad de consumo de la población, el incremento en el número de personas subalimentadas ${ }^{12}$, las dificultades para acceder al dinero en efectivo $^{13}$, el progresivo

en 10.000.000\% para 2019. Este escenario está sujeto a significativos riesgos a la baja, ya que la adopción de políticas inadecuadas para estabilizar la economía en medio de la actual fragilidad socioeconómica podría exacerbar rápidamente la difícil situación económica del país.

8. De acuerdo a la Federación Farmacéutica Venezolana (FEFARVEN) para octubre de 2018, la escasez de medicamentos alcanzó el $85 \%$. Esto tiene como correlato la aparición de enfermedades erradicadas como: malaria, difteria, sarampión, dengue, mal de chagas, meningitis, tétanos y tuberculosis, entre otras; así como, la muerte de personas con enfermedades crónicas.

9. La información publicada por el Centro de Documentación y Análisis Social de la Federación Venezolana de Maestros (CENDAS), da cuenta de que el precio de la Canasta Alimentaria Familiar (CAF) de noviembre de 2018 se ubicó en 121.719,00 Bolívares Soberanos, aumentando un $132,6 \%$ con respecto al mes de octubre de 2018, y para cuya adquisición se requieren 67,6 salarios mínimos (para la fecha fijado en 1.800,00 Bolívares Soberanos). Por su parte Oscar Meza, director de la referida institución informó que en 2019 la familia venezolana requiere al menos 300 dólares mensuales para cubrir el costo de los alimentos y 600 dólares para la canasta básica.

10. Según la Encuesta sobre Condiciones de Vida en Venezuela, entre 2014 y 2017 la pobreza por ingreso pasó de 48,4\% a $87 \%$, la pobreza extrema creció de $23,6 \%$ a $61,2 \%$ y los no pobres pasaron de $51,6 \%$ a 13\% (España y Ponce, 2018). En el último informe anual del Programa de Naciones Unidas para el Desarrollo (PNUD) publicado en el año 2018, sobre el Índice de Desarrollo Humano (IDH), solo Siria, Libia y Yemen -tres países con prolongadas guerras-, han perdido más puestos en el IDH que Venezuela; país que de acuerdo a la ONU (2018) ha retrocedido 16 puestos en el ranking mundial del IDH durante el período.

11. De acuerdo al informe "Perspectivas de la economía mundial" del Fondo Monetario Internacional (2018b), se estima que el desempleo en Venezuela durante el año 2018 alcanzó el 34,3\% y se prevé que este continúe aumentando durante 2019 para ubicarse en $38 \%$.

12. De acuerdo al informe "Panorama de la seguridad alimentaria y nutricional en América Latina y el Caribe" publicado en 2018 por La Organización de las Naciones Unidas para la Alimentación y la Agricultura (FAO), la República Bolivariana de Venezuela es el segundo país que requiere una mayor atención, puesto que la prevalencia del hambre casi se ha triplicado entre el 2010-2012 (3,6\%) y el 2015-2017 (11,7\%). Además, el número de personas en dicha situación de sub-alimentación aumentó significativamente durante ese periodo, alcanzando los 3,7 millones de personas; por lo cual se han perdido los muy importantes avances que el país había alcanzado en la década del 2000.

13. La proporción de monedas y billetes en relación con el total de liquidez se ubicó en 1,51\% en la semana concluida el 29 de junio de 2018, de acuerdo con el Banco Central de Venezuela. Según los expertos el ratio debe rondar entre $10 \%$ y 12\%, relación que se colapso de los servicios públicos como salud, electricidad, agua potable, gas, transporte público, telecomunicaciones ${ }^{14}$, lo cual, aunado a la merma de derechos civiles y políticos ha profundizado y agudizado las desigualdades, así como formas de discriminación y violencia que ya existían en la sociedad venezolana. Estos se han constituido como factores de expulsión de los venezolanos, quienes cada vez más buscan otros destinos en América Latina, pero también en otros países del mundo.

Pero conocer las cifras reales de la población venezolana que se ha convertido en migrante internacional en los últimos años sin lugar a dudas constituye una dificultad debido a la opacidad y secretismo estadístico que persiste en Venezuela ${ }^{15}$. las disparidades en lo que refiere los medios de recopilación y análisis de datos sobre migrantes en los diferentes países de la región, la poca atención prestada a los registros de salida por parte de los sistemas de migración de estos países, aunado a las limitaciones de las diferentes administraciones migratorias para monitorear y sistematizar el número de migrantes venezolanos que permanecen en sus países en condición de irregulares.

Sin embargo, según Ochoa y la ACNUR, el número de refugiados y migrantes de Venezuela en todo el mundo para octubre de 2018 han alcanzado los tres millones, cifra que representa alrededor del $9 \%$ de la población del país ${ }^{16}$

mantenía en 5,5\% al cierre del 2017. Banca \& Negocios, Relación dinero efectivo/liquidez cae a un nuevo mínimo histórico, 10 de julio de 2018 .

14. Esta precarización del sistema de servicios públicos pese a ser reiteradamente desatendida e invisibilizada por el gobierno nacional, fue reconocida en el mes de julio de 2018, cuando el ejecutivo aprobó un "plan de recuperación" de los servicios públicos. El Impulso, Maduro aprueba "plan de recuperación" para atender crisis en servicios públicos, 4 de julio de 2018.

15. La opacidad oficial con respecto a las cifras de lo que ocurre en el país es generalizada y abarca diferentes áreas; lo cual también se hace manifiesto en lo que refiere a la rendición de cuentas y el acceso a la información. Esta situación abre espacios para que desde distintas instituciones, organizaciones y fundaciones se presenten datos elaborados con metodologías diversas, en muchos casos de cuestionada rigurosidad, así como, con un marcado sesgo político-partidista.

16. Ante esta problemática el discurso oficial se ha caracterizado por negar minimizar o trivializar el fenómeno, así como, las causas que lo motivan para invisibilizar la severa crisis que experimenta el país. De acuerdo a ello, el Presidente de la República y otros funcionarios califican la migración de venezolanos como "una campaña contra el país", "un montaje", "fake news" o "falso positivo". Con frecuencia se afirma que los migrantes venezolanos son parte de la burguesía apátrida conformada por gente rica o de clase media, hijos de migrantes europeos, quienes en el menor de los casos se van engañados por la oposición política y en el mayor de ellos, abandonando 
Gráfico 1. Principales destinos de los migrantes venezolanos al 2018

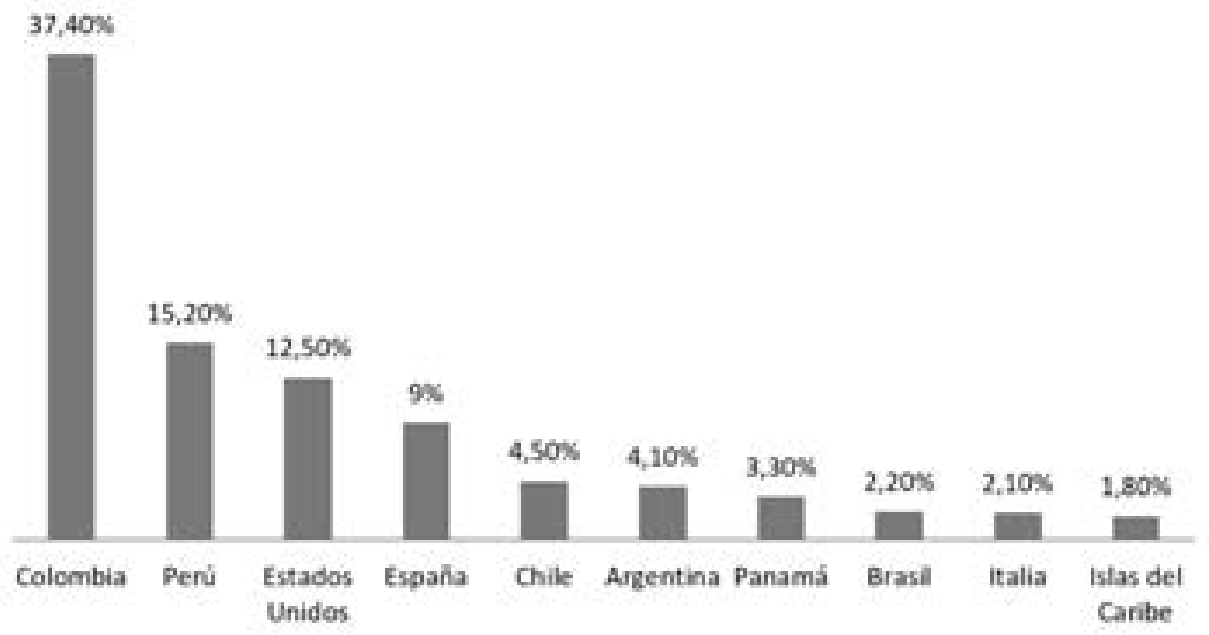

Fuente: Organismo de las Naciones Unidas para la Migración (OIM, 2018b)

De estos aproximadamente 2,4 millones se encuentran en los países de América Latina y el Caribe, mientras que los restantes 600.000 se encuentran en otras regiones ${ }^{17}$. Según la OIM (2018b) los principales destinos de la migración venezolana son países como Colombia $(37,4 \%)$ y Perú $(15,20 \%)$, seguidos de EEUU $(12,5 \%)$ y España (9\%); los cuales conforman el destino de aproximadamente el $74 \%$ de los migrantes venezolanos. No obstante, también los destinos se han diversificado hacia otros países como Chile $(4,5 \%)$, Argentina $(4,1 \%)$, Panamá $(3,3 \%)$, Brasil $(2,2 \%)$, Italia $(2,1 \%)$, las Islas del Caribe $(1,8 \%)$, entre otros. Así mismo, cuando se analizan las cifras del ACNUR correspondientes al año 2018, es posible observar cómo las solicitudes de asilo y refugio también han aumentado al menos en un

el país llevando cuantiosas sumas de dinero. Así mismo, y ante la innegable magnitud de esta situación y sus repercusiones a nivel internacional, el gobierno nacional ha intentado evadir la situación esgrimiendo que durante los últimos 18 años se han invertido cuantiosas sumas de dinero en políticas sociales para inmigrantes colombianos, ecuatorianos y peruanos, por las cuales incluso se ha llegado a reclamar indemnización.

17. Pese a ello, persiste una zona gris en cuanto a las cifras de migración internacional de venezolanos pues, con frecuencia estas no incluyen a los migrantes con doble nacionalidad -los cuales no son registrados como extranjeros al momento de su entrada al país destino-, y no incorporan a los migrantes en condición de irregulares.
$5.319 \%$ entre 2014 y 2018, pasando de 3.975 en 2014 a 215.417 en 2018.

En lo que respecta a las características de estos migrantes venezolanos, según Anitza Freitez (2018) con base a la Encuesta sobre Condiciones de Vida Venezuela (ENCOVI) correspondiente al año 2017 y realizada en articulación por la Universidad Católica Andrés Bello, la Universidad Central de Venezuela y la Universidad Simón Bolívar, en promedio se reportaron 1,3 emigrantes por hogares, de modo que se estima que entre los años 2012 y 2017 han debido emigrar al exterior algo más de 815 mil personas. El 11,7\% de ellas migraron durante 2015, el 38,5\% abandonó el país durante 2016 y el 40,3\% lo hizo en el año 2017; es decir, casi el $80 \%$ de la emigración reciente desde Venezuela ha salido básicamente durante los años 2016 y 2017. Según esta encuesta 616.423 hogares venezolanos cuentan con emigrantes internacionales, de estos, el 58\% tiene 1 emigrante, el $23 \%$ tiene 2 emigrantes, el $10 \%$ tiene 3 emigrantes, el $6 \%$ tiene 4 emigrantes y el $2 \%$ de los hogares tiene 5 emigrantes o más. El 33\% de los emigrantes provienen de la Gran Caracas, $27 \%$ de las ciudades principales, $19 \%$ de ciudades medianas y el $21 \%$ de ciudades pequeñas y caseríos; así mismo, el 35\% de los 
emigrantes pertenece al Q5 (quintil más rico de la población), el 17\% al Q4, el 20\% al Q3, el 16\% al Q2 y el 12\% al Q1 (Quintil más pobre).

El 88\% de estos migrantes se encuentra en edad de trabajar, oscilando entre los 15 a los 59 años; respecto a la motivación para migrar la ENCOVI 2017 registró que el $67 \%$ se fue en busca de trabajo, $2 \%$ por cambio de trabajo, $2 \%$ por estudio, $2 \%$ por reagrupación familiar, $2 \%$ por matrimonio o unión, $1 \%$ por motivos de salud, $5 \%$ por violencia e inseguridad, $3 \%$ por razones políticas, y $15 \%$ por otros motivos. Respecto a los destinos destacan países latinoamericanos como Colombia, Panamá, Chile, Argentina, Perú y Ecuador.

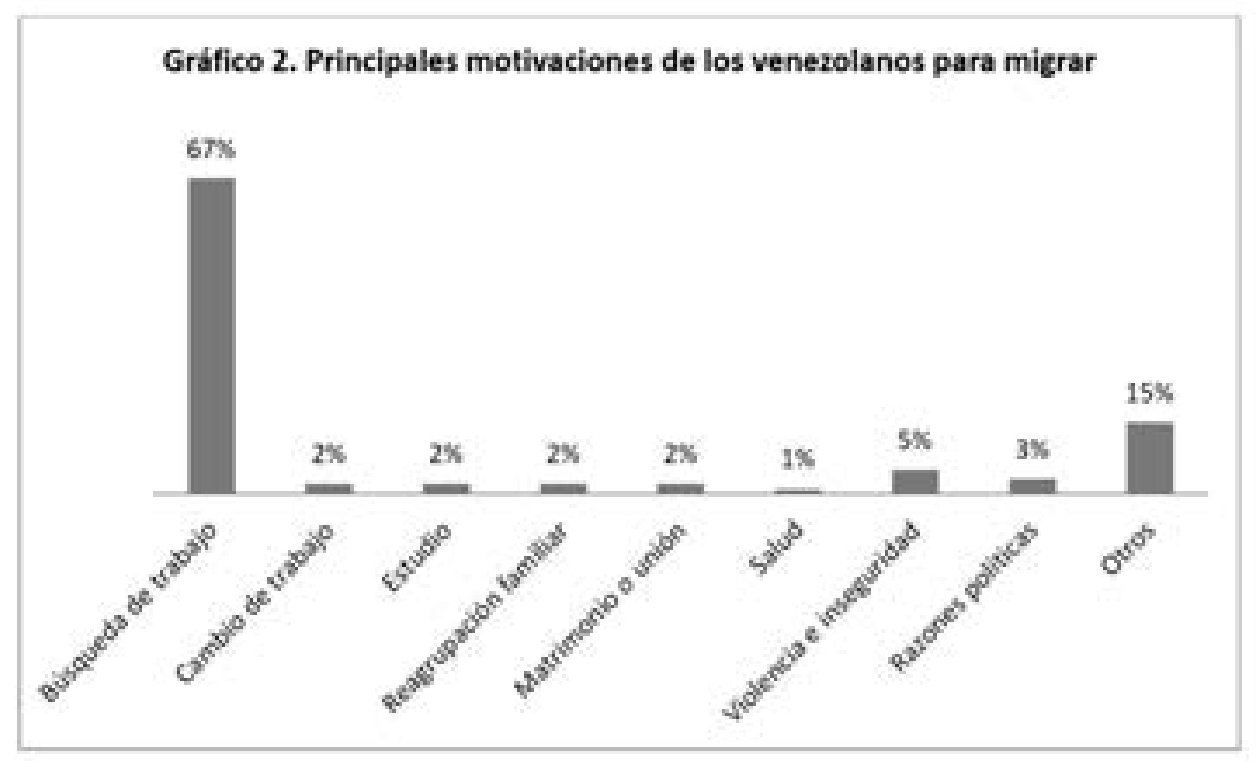

Fuente: Anitza Freitez (2018) Encuesta sobre Condiciones de Vida Venezuela 2017 ENCOVI. Emigración.

Según el "Informe Sobre la Movilidad Humana Venezolana. Realidades y Perspectivas de Quienes Emigran" realizado por los investigadores Bermúdez, Mazuera, Albornoz y Morffe (2018) a partir de la consulta a 14.578 venezolanos que emigraron entre el 9 de abril al 6 de mayo de 2018, el 59,2\% de los emigrantes venezolanos entrevistados tienen estudios universitarios ${ }^{18}$ y el $14,4 \%$ tuvieron que abandonar sus estudios al decidir emigrar. Este informe también visibiliza que el 93,9\% de los migrantes tiene como propósito enviar remesas a su hogar de origen; las cuales en el 48,6\% de los casos están destinadas a la madre, en $18,5 \%$ de los casos serán enviadas a la pareja, el 16\% las enviarán a otras personas, el 8,3\% las destinará al padre, en el 7,6\% de los casos estarán destinadas a los hijos, y en el $1,1 \%$ de los casos los receptores de remesas serán los hermanos del migrante.

Por su parte, otro elemento de importancia es que muchos de estos migrantes lo hacen sin información ni planificación, lo cual dificulta su proceso de inserción en los países de destino, así como de éxito en el proyecto emprendido. De acuerdo al "Informe Sobre la Movilidad Humana Venezolana. Realidades y Perspectivas de Quienes Emigran”, el 16\% de los migrantes no había averiguado previamente sobre la forma de vida del país que tenía como destino, al 4\% no lo esperaba nadie a su arribo y el 4,4\% no tenía un sitio donde llegar. Este hecho pone en evidencia lo señalado por la OIM (2018a) según la cual, los migrantes cada vez más se atreven

18. Según Tomás Páez para el año 2016 más de 883.000 profesionales se habían ido del país, un 90\% de estos emigrantes eran universitarios, un $40 \%$ tenía maestría, un 12\% doctorado y/o posdoctorado. Noticiero Digital, Tomás Páez: Casi 2 millones de venezolanos han emigrado en los últimos 17 años, 30 de junio de 2016. 
a dejar sus tierras sin la suficiente información; privilegiando aquella procedente de familiares y personas cercanas de su entorno social, así como, confiando cada vez más en información sobre procesos migratorios proveniente de redes sociales, empero:

Debido a que se confía más en los círculos sociales que en las fuentes oficiales, puede ocurrir que los migrantes consideren que ciertas informaciones válidas no son veraces, como la información gubernamental sobre las políticas migratorias, y que ello reduzca las probabilidades de que dichas informaciones influyan en sus decisiones de migrar (OIM, 2018a: 199).

Con frecuencia los venezolanos migran hacia países que no conocen y sobre los cuales no han investigado, con los cuales no tienen ningún tipo de vínculos, países que no se encuentran necesariamente entre sus preferencias, pero eligen al resultar más accesibles en términos económicos. Así mismo, cada vez más las personas pertenecientes a los sectores con menos recursos económicos y poder adquisitivo, ante la imposibilidad de acceder a los viajes o a la documentación necesaria -ya sea por las restricciones impuestas por las instituciones de competencia o los altos costos de los mismos-, emprenden hacia nuevos destinos en condición irregular ${ }^{19}$, principalmente a través de rutas o medios de transportes no autorizadas o de alto riesgo.

Esta desinformación y la desesperación de muchos migrantes por salir de la miseria y mejorar sus condiciones de vida ante un escenario que parece no mejorar, les impulsa muchas veces a entrar en contacto con personas que "anuncian servicios de migración, tanto legítimos como ilegítimos, por ejemplo, agencias de viaje y contratación, $y$ traficantes que venden documentos de identidad y visados falsos" (OIM, 2018a, p. 199); coyuntura que aumenta los riesgos y niveles de vulnerabilidad de esta población, y favorece su captación por redes de trata de personas y de explotación. Además:

19. De acuerdo a la OIM (2018a) la migración irregular hace referencia al movimiento que se produce al margen de las normas reguladoras de los países de envío, tránsito y recepción. Desde la perspectiva de un país de destino, la migración irregular puede implicar la entrada, la estancia o el trabajo en dicho país sin la autorización o los documentos necesarios y exigidos en virtud de las disposiciones de inmigración. Desde la perspectiva de un país de envío, la irregularidad puede consistir en el incumplimiento de los requisitos administrativos para salir del país, o la salida de dicho país sin un pasaporte o documento de viaje válido.
Los países de acogidas no son necesariamente la respuesta anhelada, pues dada la precariedad en la que están insertos por estar en la clandestinidad -sobre todo si se vive en condición irregular- pueden llegar a padecer en carne propia también el drama de la discriminación, viéndose obligados a soportar la tacha de la élite social que los estigmatiza como los "Otros" (Palacios, 2016: 148).

Finalmente, también es importante tener en cuenta que, si bien la profunda crisis económica que se vive en Venezuela ha impulsado y continua impulsando a la población de los diferentes estratos sociales a migrar ante la imposibilidad de garantizar y satisfacer sus necesidades básicas, así como, mejorar sus condiciones y calidad de vida en el país en el corto o mediano plazo; también es cierto que se evidencia la creación y consolidación de una cultura de la migración ${ }^{20}$; perspectiva en la cual la migración internacional es continuamente idealizada, promovida y exacerba como la mejor o la única opción para las personas.

Esta situación cobra una mayor magnitud con la puesta en práctica de presiones por parte de los grupos de pares (quienes consideran la migración como una condición de status y de éxito) pero también por parte de los familiares (quienes cada vez más impulsan y exigen a los más jóvenes migrar para mejorar la situación económica del grupo familiar mediante el envío de remesas), incluso sobre personas que no tienen planes de migrar o preferirían permanecer en su país. En este contexto, como bien lo señala el Informe Sobre las Migraciones en el Mundo de la OIM (2018a), muchas personas se sienten presionadas por la "cultura de migración" de su comunidad, en la cual la migración se convierte en una competencia y se estigmatiza a quienes deciden permanecer en su país o no pueden trasladarse a otros sitios; afectando y condicionando sus procesos de toma de decisiones.

\section{La migración venezolana hacia Colombia}

20. Según la OIM (2018a) las “culturas de migración”, pueden describirse como aquellas culturas en que las personas que no han migrado observan a los migrantes con los que mantienen un vínculo social e intentan emular su comportamiento migratorio. Se ha observado que la creación de este tipo de culturas influye en el modo en que los migrantes potenciales imaginan su futuro: los jóvenes que crecen y alcanzan la mayoría de edad cada vez tienen más expectativas de migrar a otros países a lo largo de su vida. 
Ante la severa crisis que atraviesa Venezuela, una parte importante de la población ha optado por la migración como el principal mecanismo para paliar y superar el acelerado deterioro de las condiciones y calidad de vida, la precarización del salario, el sub empleo, así como, las dificultades para acceder a la alimentación, la salud, la educación y los servicios públicos. En este contexto el destino por excelencia ha sido y continúa siendo Colombia, por la cercanía física con Venezuela, los menores costos de traslado, las similitudes culturales y la historia de migración compartida por ambos países. En este contexto muchos han optado por tramitar o hacer uso de su segunda nacionalidad (según la OIM 2018b un 40\% son colombo-venezolanos), mientras que otros han decidido vender sus propiedades (casa, vehículo, muebles, dispositivos electrónicos, ropa, entre otros) para emprender camino; principalmente a través de las fronteras y recurriendo al transporte terrestre e incluso a interminables caminatas, situación que ha convertido a Colombia en el país con más migrantes venezolanos.

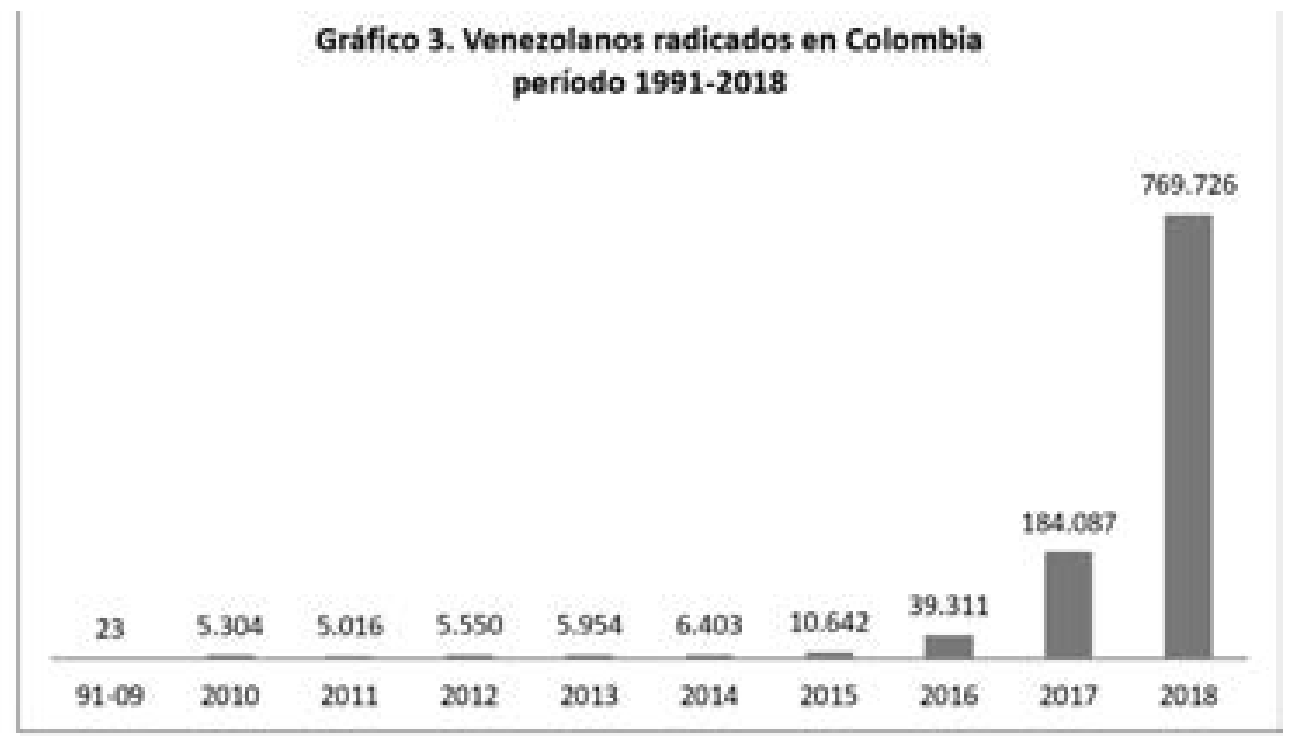

Fuente: Migración Colombia. (2018). Todo lo que quiere saber sobre la migración venezolana y no se lo han contado.

Al respecto y según la información disponible en el informe "Todo lo que quiere saber sobre la migración venezolana y no se lo han contado" publicado en el mes de diciembre de 2018 por Migración Colombia, se evidencia un claro incremento en el número de venezolanos que han llegado al país en los últimos tres años, con la intención de radicarse. Al 30 de septiembre del año 2018 en Colombia había 1.032 .016 venezolanos, de ellos 573.502 es decir, el 55,5\% se encuentran en territorio colombiano como regulares ${ }^{21}, 240.416$ lo que equivale a $23,2 \%$ se encuentran en Proceso de Regularización ${ }^{22}$, y 218.098 lo que representa el 21,1\% se encuentran en condición de Irregulares ${ }^{23}$. Además, según lo evidencia el informe "Migración desde Venezuela

21. Según Migración Colombia, la condición de regulares hace referencia a los venezolanos con Visa, Cédula de Extranjería, Permiso Especial de Permanencia (PEP) o Dentro del Tiempo de Ley Establecido.

22. De acuerdo con Migración Colombia, en Proceso de Regularización Hace referencia a los venezolanos que se censaron en el Registro Administrativo de Migrantes Venezolanos (RAMV) y están en proceso de expedir el PEP.

23. Migración Colombia define a la población en condición de irregulares a los venezolanos que superaron el tiempo de permanencia y quedaron en condición irregular o aquellos que ingresaron por pasos no autorizados o trochas. Además, como bien señala el informe "Migración desde Venezuela a Colombia: impactos y estrategia de respuesta en el corto y mediano plazo" publicado por el Banco Mundial en 2018, la condición de irregularidad responde en muchos casos a las limitaciones en la expedición de documentación en Venezuela, así como al costo de obtenerla. La población venezolana reporta restricciones para adquirir los documentos de identidad 
a Colombia: Impactos y Estrategia de Respuesta en el Corto y Mediano Plazo" publicado en 2018 por el Banco Mundial con base a las estadísticas de Migración Colombia, durante los primeros 9 meses de 2018 unos 724.036 venezolanos habrían hecho tránsito por Colombia hacia otro país. etaria del 7,7\% de los migrantes. Estas ponen en evidencia que son los más jóvenes quienes migran, pero también que las motivaciones y posibilidades de migrar disminuyen con el aumento de la edad, situación que puede tener como consecuencia a mediano y largo plazo un significativo envejecimiento de la sociedad venezolana.

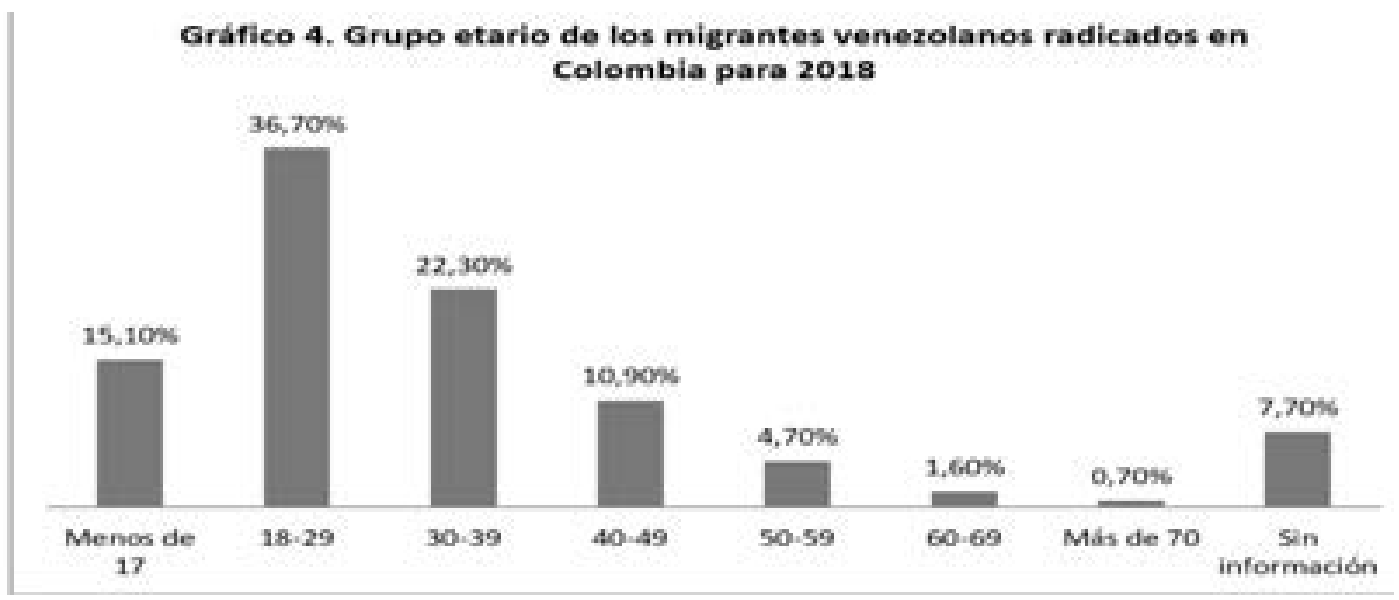

Fuente: Migración Colombia. (2018). Todo lo que quiere saber sobre la migración venezolana y no se lo han contado.

Según Migración Colombia (2018) del total de 1.032.016 venezolanos radicados en Colombia, el $44 \%$ son mujeres, $48,1 \%$ son hombres, $0,03 \%$ son personas transgéneros y no se especificó la información en 7,7\% de los casos. En lo que refiere al grupo etario de la población de migrantes venezolanos el $15,1 \%$ son menores de 17 años, $36,7 \%$ tienen entre 18 a 29 años, $22,3 \%$ tienen edades comprendidas entre 30 a 39 años, $10,9 \%$ pertenecen al grupo con edades entre 40 a 49 años, $4,7 \%$ tienen entre 50 a 59 años, $1,6 \%$ de las personas migrantes tienen entre 60 a 69 años, 0,7\% pertenecen a la población con más de 70 años y no se dispone la información del grupo

necesarios para entrar de formar regular (o regularizar su estatus migratorio una vez en Colombia a través de instrumentos como el PEP), como registros de nacimiento apostillados y pasaportes. Dichas restricciones incluirían la no expedición de los documentos mencionados por parte del Gobierno venezolano, su costo de obtención o el vencimiento, así como, el robo o pérdida de los documentos durante el proceso migratorio. Otro dato importante aportado por Banco Mundial (2018) es que la población de migrantes venezolanos irregulares está conformada por un alto porcentaje de poblaciones vulnerables, incluyendo mujeres $(49,7 \%)$, menores de edad (27\%), población perteneciente a grupos étnicos, incluyendo indígenas, en su mayoría de la etnia wayuu (6\%), adultos mayores (2,6\%), mujeres en estado de embarazo (2\%) y personas con alguna discapacidad $(2,6 \%)$
Por otra parte, la Matriz de Monitoreo del Desplazamiento implementado por la OIM (2018b) y Migración Colombia ha logrado obtener un perfil más claro de estos migrantes procedentes de Venezuela, según su nacionalidad: Un $40 \%$ son colombovenezolanos, un $30 \%$ son venezolanos, un $30 \%$ son colombianos. Esta información es de suma importancia para comprender las particularidades de la migración proveniente de Venezuela que se instala en Colombia, y que evidencia los lazos históricos de la migración entre ambos pueblos. De alguna manera están retornando a su país de origen las nuevas generaciones de colombianos, cuyas padres décadas atrás buscaban mejores condiciones de vida en Venezuela. Asimismo, hay 1.600 .000 venezolanos con Tarjeta de Movilidad Fronteriza, se trata de una migración pendular de los ciudadanos que residen en la zona de frontera y se mueven habitualmente entre los dos países. Colombia además sirve de puente hacia terceros destinos como Ecuador, Perú, Chile, EEUU, Panamá, México, España, Argentina, Brasil y Costa Rica.

Respecto a la ubicación geográfica de los migrantes venezolanos, según Migración Colombia más del $60 \%$ se han concentrado principalmente en 5 departamentos, entre ellos: Bogotá donde se han 
radicado el 23,1\%, Norte de Santander donde se ha contabilizado el 14,7\%, La Guajira con el 11,9\% de venezolanos, Atlántico donde radican el 10,2\% de los migrantes y Antioquia donde hacen vida el 6.9\% de los venezolanos radicados en Colombia.

No obstante, Colombia al ser un país con significativos grados de vulnerabilidad y desigualdad, además de encontrarse en un periodo de post-conflicto, también se está viendo afectada por la migración masiva de venezolanos hacia su territorio. De acuerdo al citado informe del Banco Mundial (2018) la llegada acelerada y en una proporción relativamente alta de venezolanos en condiciones de vulnerabilidad socioeconómica -el $90 \%$ de los migrantes afirma haber dejado Venezuela por falta de comida y el $82 \%$, por falta de trabajo (OCAH, 2018)-, está colocando presiones en las instituciones, los sistemas de provisión de servicios, el mercado laboral y las dinámicas sociales de este país receptor, entre las que destacan: 1) El desbordamiento de la demanda de servicios como salud ${ }^{24}$, vivienda ${ }^{25}$, educación, protección social, agua, saneamiento y otros. 2) El importante incremento de casos de sarampión y difteria, enfermedades antes erradicadas, así como, de tuberculosis y paludismo. 3) El aumento del empleo informal, el subempleo, y el aumento acelerado de la demanda de trabajo, la cual afecta los niveles de empleo, su calidad y puede contribuir en la disminución de los salarios reales. 4) El afloramiento de tensiones entre la población local y migrantes explicado por la mayor competencia por recursos que de por sí ya eran escasos; situación que se agrava en las zonas fronterizas caracterizadas por sus déficits de desarrollo, su afectación por el conflicto armado y la concentración de su economía en industrias extractivas.

\section{Prejuicios, estereotipos y criminalización de los migrantes venezolanos}

La migración en las diferentes etapas del proceso histórico social ha enfrentado

24. Según el Banco Mundial (2018) la atención en salud a migrantes venezolanos en Colombia creció de 125 casos en 2014 a casi 25 mil en 2017.

25. De acuerdo a lo señalado en el informe publicado por el Banco Mundial (2018), la migración venezolana en Colombia ha generado una demanda importante en materia de albergue temporal y vivienda, esta al no poder ser satisfecha se ha traducido en la ocupación de espacios públicos y el crecimiento de los asentamientos informales en zonas de riesgo. prohibiciones, limitaciones y detracciones, sin embargo, estas se profundizan cuando los migrantes pertenecen a grupos sociales tradicionalmente precarizados, vulnerados y estigmatizados. Es decir, si bien aún en la actualidad una cantidad no poco significativa de personas se resisten a la migración en sus países sobre la base de criterios nacionalistas, chauvinistas, culturalistas y racialistas, la mayoría de las personas que se declaran opuestas a los procesos y flujos migratorios se resisten es a albergar en sus países a migrantes precarizados, empobrecidos, racializados y pertenecientes a los grupos sociales considerados minorías, esto quiere decir, estigmatizados y tradicionalmente subalternizados.

Estas posturas con frecuencia son alimentadas por las narrativas político partidistas y mediáticas televisivas desfavorables, negativas y estereotipadas sobre los migrantes, donde son presentados como personas incapaces de integrarse adecuadamente, peligrosos $y$ amenazadores para la integridad física de los nacionales, pero también como una amenaza a sus propiedades, a sus empleos, su cultura, su herencia étnica, su lenguaje y su identidad; es decir, convertidos en chivos expiatorios pues, respecto a la migración "las bases factuales, la información y los análisis equilibrados que componen una visión histórica del fenómeno, así como implicaciones estratégicas, parecen quedar al margen o atraer escasa atención en las discusiones y los debates políticos, públicos y mediáticos -generalmente polarizados-" (OIM, 2018a: 2).

Ante el boom publicitario de la seguridad ciudadana, que relacionan al inmigrante con la delincuencia, estampa en aquellos no solo la etiqueta de la marginalidad, sino la cruel consecuencia, como expresa Zaffaroni, de ser el "diferente", recién llegado, y por ende, más desconocido (Palacios, 2016, p. 149). Por su parte, otras narrativas políticas y mediáticas presentan a los migrantes como sujetos extremadamente vulnerables, como víctimas, los cuales deben ser merecedores de lastima y de la ayuda caritativa; invisibilizando las fortalezas, capacidades y potencialidades de los migrantes, los cuales según la OIM aportan a la economía y el PIB de los países de acogida, incrementan la oferta de mano de obra en sectores y ocupaciones con escasez de trabajadores y ayudan a corregir los desequilibrios del mercado de trabajo tanto en 
los sectores cualificados como también en las menos cualificadas. Adicionalmente y contrario al imaginario colectivo, la OCDE (2013) ha puesto en evidencia que los efectos fiscales netos de la inmigración - esto es, los impuestos que pagan los migrantes menos los beneficios y los servicios públicos que reciben - suelen ser muy reducidos y generalmente positivos; sin embargo, esta situación con frecuencia es invisibilizada por los medios de comunicación.

En el caso que nos ocupa, la reciente migración venezolana ha convertido a esta población en el nuevo chivo expiatorio de la sociedad colombiana, siendo responsabilizados por los niveles de desempleo, la disminución de la calidad de vida, e incluso, por el "aumento de las infidelidades" y la "desintegración familiar"26. Pero el flujo de venezolanos en condición de vulnerabilidad hacia la nación colombiana también ha dado paso a una mayor percepción de inseguridad, motivo por el cual son continuamente responsabilizados por los índices de inseguridad y delincuencia ${ }^{27}$.

26. "A los problemas de inseguridad e invasión del espacio público por parte de los venezolanos, se suma que algunas mujeres del vecino país están desintegrando los hogares santandereanos y los casos de infidelidad han aumentado" Caracol, Denuncian desintegración familiar por éxodo de venezolanos, 29 de agosto 2018.

27. Sin embargo, no significa esto que los migrantes venezolanos no participen en actividades irregulares e ilegales durante su permanencia en Colombia. De acuerdo al informe "Inseguridad, violencia y economías ilegales en las fronteras. Los desafíos de nuevo gobierno" publicado durante 2018 por la Fundación ideas para la paz (FIP), los migrantes venezolanos se encuentran en riesgo de ser reclutados por grupos armados al margen de la ley y de ser incorporados como mano de obra en diferentes economías ilegales; además, existe evidencia de que los migrantes venezolanos se han vinculado a actividades ilegales como: 1) Trata de personas, que en el último año ha afectado a mujeres y niñas venezolanas dadas las dinámicas crecientes de explotación sexual. 2) La producción de drogas trabajando como recolectores. Además, participan en el trasporte de sustancias y contrabando lo que genera diferentes situaciones de vulnerabilidad. 3) La vinculación como combatientes a los grupos armados ilegales, entre estos al Ejército Popular de Liberación (EPL) y, en menor medida, al Ejército de Liberación Nacional (ELN). El informe "Migración desde Venezuela a Colombia: impactos y estrategia de respuesta en el corto y mediano plazo" publicado por el Banco Mundial (2018) alerta sobre la utilización por parte de los actores armados y estructuras criminales de niños y niñas venezolanos para la realización de actividades ilícitas. En Arauca, se han identificado casos de niños de 10 y 11 años que han sido utilizados para distribuir y vender droga. Por su parte un reportaje de Reuters (2018) visibiliza que la organización Terre des Hommes que durante el mes de agosto de 2018 encuestó a más de 900 personas, en su mayoría inmigrantes venezolanos a lo largo de la frontera, llama la atención sobre el hecho de que los niños venezolanos están siendo alquilados para mendigar en las calles, en los semáforos y como trabajadores domésticos.
En la encuesta Cúcuta cómo vamos en 2017, el $66 \%$ de los encuestados considera que la migración de venezolanos representa una amenaza para la ciudad. Por su parte, funcionarios de la Cámara de Comercio de La Guajira reportaron que, en una encuesta de percepción realizada por esta entidad, el $33 \%$ de los comerciantes respondió que los altos niveles de delincuencia en los sectores comerciales del municipio se explican por el aumento de los migrantes venezolanos (Banco Mundial, 2018: 85).

Sin embargo, como lo explica el informe del Banco Mundial (2018), los datos muestran que, en general, los niveles de victimización en áreas receptoras son los mismos o incluso menores que antes de la migración. Además ante la migración de esta población venezolana vulnerable y empobrecida también se han desarrollado concepciones y prácticas de rechazo, estigma y xenofobia ${ }^{28}$ que, en algunos casos se han tornado violentos $^{29}$. La OIM encontró que, de 2.335 encuestas realizadas a migrantes venezolanos en zonas de frontera en Colombia durante 2018, el $27 \%$ reporta haber sufrido algún hecho de discriminación, en poblaciones como Subachoque, Cundinamarca, Arauca y Cúcuta han circulado panfletos amenazando a la población venezolana;

28. Ante los diferentes episodios de discriminación, violencia y vulneración de derechos sufridos por algunos migrantes venezolanos en los países destino -específicamente posterior a los ataque sufridos en el Estado de Roraima en Brasil durante el mes de agosto de 2018-, ha sido creado por parte del gobierno venezolano el plan "Vuelta a la Patria", el cual destaca entre sus objetivos facilitar el retorno de venezolanos al país y su inserción en el sistema de protección social; sin embargo, el abordaje y el tratamiento mediático de esta política se ha caracterizado por su empleo propagandístico, enfatizando en los episodios de xenofobia, violencia y victimización experimentadas por los venezolanos en los países receptores, desconociendo e invisibilizando el apoyo prestado por los ciudadanos y los gobiernos de estos países; así como, desatendiendo las causas estructurales que generaron el flujo migratorio. Al respecto y según las últimas cifras publicadas por el Ministerio del Poder Popular para Relaciones Exteriores el 29 de diciembre de 2018, un total de 11.872 venezolanos han sido repatriados, 6.886 provenientes de Brasil, 1.902 de Perú, 1.817 de Ecuador, 554 de Colombia, 186 de República Dominicana, 344 de Argentina, 182 de Chile y 1 de Panamá. Además entre las motivaciones para regresar a Venezuela el $54 \%$ precisó como motivo de retorno el constante hostigamiento en el país receptor, denunciando fuertes episodios de xenofobia, explotación, maltrato laboral y social.

29. Esta animadversión contra los migrantes venezolanos en Colombia según el Banco Mundial (2018), parece responder primordialmente a la expulsión de colombianos de Venezuela en el año 2015 -y desde nuestra perspectiva, aunado a la estereotipación y estigmatización de la población colombiana como "bachaqueros" (personas que practican el contrabando de extracción), lo cual ha generado un sentimiento de rechazo hacia el país vecino. 
en Cúcuta y Arauca se han registrado ataques con bombas molotov a lugares de albergue y asentamientos, y, en casos extremos, el asesinato de migrantes venezolanos ${ }^{30}$.

\section{Migración, vulnerabilidad y género: Trata, prostitución y femicidio/ feminicidio $^{31}$}

Los patrones migratorios desde una perspectiva de género también han cambiado en las últimas décadas, donde las mujeres se han convertido en protagonistas de los procesos emergentes de migración internacional. De acuerdo a la OIM (2018a), el 52\% de los migrantes internacionales son hombres, y el $48 \%$ son mujeres, es decir, presenciamos un proceso de feminización de la migración $^{32}$. Este cambio no es solo de carácter cuantitativo sino también de carácter cualitativo pues, cada vez más las mujeres migran de forma independiente, se insertan en el mercado laboral de los países destino (principalmente en los sectores de servicios y asistencia), al mismo tiempo que asumen la carga familiar en sus hogares de origen y su sostenimiento mediante el envío de remesas, lo cual sin lugar a dudas trastoca los procesos interactivos, organizativos y los procesos de toma de decisiones ${ }^{33}$.

Ahora, si bien la migración tiene un impacto positivo en lo que refiere al mejoramiento de las oportunidades y calidad de vida de las migrantes, favorece el empoderamiento y la autonomía económica, social y personal; también es cierto

30. El Instituto Nacional de Medicina Legal de Colombia informó que entre enero y septiembre de 2018 han fallecido 310 venezolanos en este país, teniendo en cuenta que para los mismos meses de 2017 se reportaron solo 90, puede afirmarse que hubo un aumento del 244\%. La mayoría de los casos fueron homicidios (56\%) seguidos de tránsito (19\%), muertes accidentales (18\%), suicidios (7\%). El perfil de las víctimas por sexo fue de hombres en un $81,9 \%$ y mujeres 18,1\%. El espectador, Informe de Medicina Legal reveló incremento de muertes de venezolanos en Colombia, 22 de octubre 2018

31. Se incluyen ambos términos debido a que este delito está tipificado como femicidio en Venezuela y como feminicidio en Colombia.

32. Según la OIM y el Ministerio de Desarrollo Social del Gobierno de la Ciudad Autónoma de Buenos Aires (2014), el concepto de la feminización de la migración internacional alude por un lado, a la creciente participación y aceleración de las mujeres en los procesos migratorios internacionales, quienes actualmente constituyen la mitad de la población migrante en el mundo (tras un leve aumento numérico); por otro, a que cada vez hay más mujeres que migran de forma autónoma, como pioneras de movimiento y en calidad de proveedoras principales para sus familias transnacionales.

33. Algunas de las ideas generales de esta sección tienen su origen en el artículo Migración, trata y femicidio: Las mujeres venezolanas en el exterior. (Pineda, 2018). que la prevalencia de las desigualdades por razones de género convierte a los procesos migratorios en una condición de riesgo para las niñas y mujeres, quienes desde el momento que inician el recorrido desde sus hogares de origen hasta los lugares de destino se enfrentan a la desprotección y a múltiples formas de violencia y desigualdad por razones de género; entre estos es posible mencionar: prejuicios, estereotipos, acoso y violencia sexual, prostitución, así como, el secuestro o captación por parte de redes de trata con fines de explotación sexual.

En el caso de Venezuela, según Pineda (2018) la precarización de las condiciones de vida ha obligado a las mujeres venezolanas a realizar dobles y hasta triples jornadas, a desertar de sus puestos de trabajo, y a recurrir a otras actividades económicas que permitan su subsistencia y la de sus familias, entre estas es posible considerar: el trabajo informal, la reventa de productos escasos, el micro contrabando de productos, la prestación informal de servicios de cuidado, la comisión de hurtos, la participación en diversos tipos de delitos, la prostitución, la mendicidad y la migración. De acuerdo a ello, y según Anitza Freitez (2018) con base a la Encuesta sobre Condiciones de Vida Venezuela (ENCOVI) correspondiente al año 2017, las mujeres representan el $49,3 \%$ de los venezolanos que han migrado hacia el exterior; mientras que el "Informe Sobre la Movilidad Humana Venezolana. Realidades y Perspectivas de Quienes Emigran" da cuenta que de los 14.578 migrantes venezolanos consultados el $44 \%$ eran mujeres, de las cuales el $53,7 \%$ son solteras.

En muchos casos estos procesos migratorios representan sin lugar a dudas una mejora en las condiciones y calidad de vida de las mujeres y sus familias, así como, en el paliativo de la precarización y sufrimiento de familiares y dependientes en el país de origen. Sin embargo, estos procesos migratorios también pueden profundizar las condiciones de vulnerabilidad y riesgo de las mujeres venezolanas. Naciones Unidas (2018) estima que un $2 \%$ de las mujeres venezolanas en el exterior con edades entre los 15 y 49 años son sobrevivientes de violencia sexual; mientras que un trabajo de investigación realizado por Efecto Cocuyo que incluyó el conteo y revisión de casos reseñados en diversos medios de comunicación desde marzo hasta el 22 de noviembre 2018, encontró que 188 
venezolanas en nueve países han sido rescatadas por autoridades judiciales de esas naciones tras haber sido víctimas de trata, 88 de ellas en Colombia, lo que equivale al $46,8 \%$ de las víctimas. Así mismo, una cantidad importante de migrantes venezolanas en Colombia se han visto en la necesidad de ejercer la prostitución como uno de los medios para atender sus necesidades económicas y la de sus familias, situación a la que se ven expuestas en mayor medida las migrantes en condición de irregulares.

De acuerdo al trabajo de investigación titulado "Caracterización de Personas que Realizan Actividades Sexuales Pagadas en Contextos de Prostitución en Bogotá 2017" realizado por el Observatorio de Mujeres y Equidad de Género de Bogotá (OMEG) de la Secretaría Distrital de la Mujer (2018), se pudo conocer que, de 7.094 personas consultadas que realizan actividades sexuales pagadas en contextos de prostitución en la ciudad de Bogotá, 2.316 de estas personas son extranjeras $32,7 \%$, y de estas extranjeras 2.312 son venezolanas 99,8\%. Esta investigación también muestra que el $84,1 \%$ de ellas se iniciaron en la actividad sexual pagada tras su llegada a Colombia y, aunque el 33,1\% de las prostitutas venezolanas en Bogotá tienen educación superior, el 36,1\% consideran que la actividad sexual pagada es la opción más rentable, $23,7 \%$ considera que es la única opción que tiene y $20,2 \%$ afirma que es la actividad a la que esta forzada a realizar.

El $6,7 \%$ de las mujeres venezolanas que se prostituyen en Bogotá continúan residiendo en Venezuela, el $71,2 \%$ viaja frecuentemente a Bogotá a prostituirse desde hace menos de 1 año,y el 20,2\% lo hace desde hace menos de 5 años. El 69,3\% de las mujeres venezolanas en condición de prostitución en la ciudad de Bogotá tienen entre 18 a 26 años, el 25,3\% tiene edades comprendidas entre los 27 a los 35 años, el 4,8\% oscila entre los 36 a 45 años y el $0,1 \%$ forma parte del grupo etario entre 46 a 59 años. Respecto al lugar donde ejercen esta actividad el 92,5\% de las venezolanas manifestó que se prostituye en algún establecimiento y el $7,3 \%$ en la calle. El $54 \%$ reside en un cuarto en el establecimiento donde se prostituye, el 7,8\% de ellas debe pagar arriendo por la habitación en el establecimiento y el 35,8\% debe pagar el arriendo con una periodicidad diaria; este hecho permite identificar los niveles de vulnerabilidad y desprotección de estas mujeres pues, si no cumplen con los mínimos de clientes exigidos y no producen el dinero suficiente para cancelar el arriendo diario no cuenta ni siquiera con un lugar donde pernoctar. Ante esta situación el $7,7 \%$ de las prostitutas venezolanas que hacen vida en Bogotá atiende al día en promedio 1 cliente, el $21,5 \%$ a dos, el $25,9 \%$ a 3 , el $16,7 \%$ a 4 , el $15 \%$ a 5 , el $4 \%$ a 6 , y $9,2 \%$ de ellas atiende a 7 personas o más al día; además por cada persona que atienden el $66,2 \%$ recibe en promedio entre $\$ 25.000$ y $\$ 50.000$ pesos colombianos (entre 8 y 16 dólares).

Tanto la Fundación Ideas para la Paz, como ONU Mujeres, documentan que con la llegada de venezolanas se dio una reducción sustancial en los precios del trabajo sexual. Evidencia anecdótica indica que las mujeres venezolanas que ejercen la prostitución lo hacen en condiciones desventajosas comparadas con las de mujeres de nacionalidad colombiana, siendo obligadas a cobrar un precio menor, adquirir sus propios preservativos y cumplir estrictas normas de horario y los lugares en los que pueden ejercer esta actividad. Esto ha generado una situación de rechazo de parte de mujeres colombianas que ejercen la prostitución $\mathrm{y}$ ahonda los sentimientos de repudio en contra de las mujeres venezolanas (Banco Mundial, 2018: 87).

La investigación "Caracterización de Personas que Realizan Actividades Sexuales Pagadas en Contextos de Prostitución en Bogotá 2017", también evidencia que de las venezolanas que se prostituyen en Bogotá el 10,3\% ha vivido violencia física por parte de los clientes, 7,6\% violencia sexual por parte de los clientes, 9,5\% violencia física por parte de otras personas que ejercen actividades sexuales pagadas, 4,3\% ha experimentado abuso policial, $2,8 \%$ violencia física por parte de las personas que la emplea en el establecimiento, al $4,5 \%$ les han sido retenidos sus papeles de identificación, $2 \%$ ha sido retenida en contra de su voluntad dentro del establecimiento, al $2 \%$ le ha sido retenido su dinero por parte del dueño del establecimiento, y el $2,1 \%$ ha sido víctima de trata de personas. Así mismo, las migrantes venezolanas en general por su pertenencia de género y su condición de migrantes se encuentran en particular riesgo 
de sufrir violencia por razones de género $y$ femicidio/feminicidio ${ }^{34}$.

De acuerdo con información del Instituto Nacional de Salud, las atenciones por casos de violencia de género entre la comunidad migrante han aumentado en un 313\%, pasando en el período analizado (semanas epidemiológicas 1 al 23 de 2017 y 2018) de 78 a 245 casos, respectivamente. Aun cuando los datos sugieren un incremento en la incidencia de este tipo de violencia, estos no permiten determinar la escala del problema, ya que la mayoría de casos no son reportados por estigma, miedo a la deportación o falta de acceso a servicios de salud (Banco Mundial, 2018: 87,88).

Esta situación de vulnerabilidad, violencia y discriminación también es experimentada por la población LGBTI. Según el informe "Crisis humanitaria de venezolanos LGBT en el Caribe" realizado por la organización Caribe Afirmativo, en el año 2018 en la Región Caribe de Colombia se registraron 23 casos de violencia contra personas LGBTI venezolanas, una mujer trans venezolana fue asesinada, cinco murieron en etapa SIDA por falta de acceso a medicamentos; se denunciaron dos hechos colectivos de violencia policial hacia mujeres trans venezolanas en espacios públicos de la región y se interpusieron 42 quejas por discriminación y xenofobia, por su nacionalidad y por su pertenencia a la población LGBTI.

\section{La rentabilidad de la migración internacional de los venezolanos}

La profunda crisis política, económica y social experimentada por la sociedad venezolana y su deriva en la migración internacional afecta a millones de personas, profundiza sus condiciones de vulnerabilidad, amplía las desigualdades, al mismo tiempo que favorece la ocurrencia de múltiples y sistemáticas formas de violencia; sin embargo, este escenario también ha sido capitalizado, exacerbado y explotado por algunos sectores, quienes ven en ellos una oportunidad de mejorar su posición económica, política y

34. Según el informe "Inseguridad, Violencia y Economías Ilegales en las Fronteras. Los Desafíos del Nuevo Gobierno" realizado en 2018 por la Fundación Ideas Para la Paz (FIP), para las mujeres venezolanas el riesgo de explotación sexual y de femicidios/ feminicidios es mayor, en el marco de su vinculación al trabajo sexual y economías ilegales. mediática a merced de los más precarizados. $\mathrm{Al}$ respecto la migración internacional de una proporción importante de la población venezolana -producida de forma masiva desde el año 2015-, ha generado saldos positivos para los detentores del poder político, económico y mediático, para la sociedad civil, así como, para las mafias y personas inescrupulosas convertidas en mercaderes de la desgracia ${ }^{35}$.

En el caso del gobierno venezolano la migración ha sido políticamente rentable al desarticular y atomizar a los grupos poblacionales que pudieran hacerle una oposición política activa, así como, al disminuir su participación electoral; aunada a ello, este proceso migratorio ha funcionado como válvula de escape de la tensión social generada por la crisis. Esta situación también ha favorecido a los gobiernos de los países receptores, principalmente mediante la conversión de los migrantes en chivos expiatorios a quienes responsabilizar por las diferentes problemáticas pre-existentes $\mathrm{y}$ emergentes, lo cual permite desviar la atención pública y mediática de sus respectivas agendas y problemas nacionales.

Otro aspecto de gran importancia es que, este escenario crea las condiciones para la captación de ingentes recursos internacionales por parte de los gobiernos anfitriones de migrantes, los cuales han recibido al menos unos 168 millones de dólares desde finales de 2016: 95 por parte de Estados Unidos $^{36}$, 40,8 de la Unión Europea ${ }^{37}$ y 32 de la $\mathrm{OIM}^{38}$; repartición de la cual el gobierno venezolano no ha querido quedar por fuera, solicitando a la Organización de Naciones Unidas 500 millones de dólares para la repatriación de venezolanos. A ello hay que sumar las innumerables fundaciones, ONG y organizaciones de la sociedad civil que solicitan cuantiosos recursos a embajadas y organismos internacionales, bajo la premisa del desarrollo de proyectos de investigación, formación y acción social orientados a favorecer a los migrantes más necesitados, proyectos que en muchas ocasiones son viabilizados por las élites de estas organizaciones, sin cumplir los

35. Algunas de las ideas generales de esta sección tienen su origen en: Ávila, $2018 a$.

36. EFE, EEUU anuncia 48 millones de dólares para refugiados y migrantes venezolanos, 25 de septiembre 2018.

37. EFE, Sánchez confirma una millonaria ayuda de la UE a Latinoamérica por la crisis venezolana, 30 de agosto 2018.

38. Noticias ONU, La OIM lanza un plan para ayudar a los migrantes venezolanos, 10 de Abril 2018. 
objetivos propuestos y sin generar impacto en los sectores de migrantes afectados. Esta situación también favorece la proliferación de "expertos" de dudosa reputación y confiabilidad, con el fin posicionarse mediáticamente, hacerse de un lugar en la agenda pública y, en consecuencia, acceder a financiamientos.

Esta situación de precariedad y vulnerabilidad de los migrantes venezolanos también ha sido convertida en una oportunidad de negocio y fuente de enriquecimiento por parte de burócratas $\mathrm{y}$ gestores, quienes ante las dificultades $\mathrm{y}$ dilaciones para el acceso a la documentación necesaria, solicitan a los migrantes cientos y miles de dólares por la formalización de documentos como: pasaportes, antecedentes penales, apostillas, legalización de documentos, entre otros. Finalmente, la migración venezolana también está siendo aprovechada por las mafias nacionales e internacionales que cada vez más captan a hombres y mujeres en redes de trata de personas, les someten a la explotación laboral y sexual, así como, incorporados bajo persuasión o coacción a grupos armados y delictivos.

\section{CONCLUSIONES}

La actual crisis política, económica, social e institucional que atraviesa Venezuela ha transformado vertiginosamente al país de receptor a emisor de migrantes; la población es continuamente expulsada por la precarización de sus condiciones de vida, lo cual les ha llevado a diversos países de la región, entre los cuales Colombia se ubica como principal destino.

$\mathrm{Al}$ respecto es posible señalar que el migrante venezolano se encuentra en búsqueda de trabajo, de fuentes de subsistencia y envío de remesas. El perfil de los que se quedan en Colombia, al menos un $40 \%$ tienen doble nacionalidad y un $30 \%$ es realmente de nacionalidad colombiana, es decir, que apenas el $30 \%$ son solo venezolanos. Esta información es de suma importancia para comprender las particularidades de la migración proveniente de Venezuela que se instala en Colombia, y que evidencia los lazos históricos de la migración entre ambos pueblos. De alguna manera están retornando a su país de origen las nuevas generaciones de colombianos, cuyos padres décadas atrás buscaban un mejor futuro en Venezuela.
Pero pese a los lazos históricos de la migración entre ambos pueblos, los venezolanos se han convertido en los chivos expiatorios de los grandes problemas nacionales, siendo señalados como los responsables de diversos males sociales: inseguridad, insalubridad, infidelidades, entre otros. La consecuencia de estos discursos xenófobos y estigmatizantes es una mayor victimización, vulnerabilidad, riesgo y precariedad en sus condiciones de vida. Esto se hace más visible en el caso de las mujeres migrantes, quienes son objeto de redes de trata, prostitución $\mathrm{y}$ violencia de género. Sin embargo, estas condiciones de vulnerabilidad de los migrantes venezolanos se han hecho rentables para diversos actores políticos y económicos, quienes obtienen múltiples ganancias gracias a este drama humano. Ante este escenario nos permitimos recomendar grosso modo, como acciones imprescindibles e impostergables a implementar:

* El reconocimiento por parte del gobierno nacional de la situación de vulnerabilidad y precarización de la población, así como, de la problemática de la migración de venezolanos, a fin de garantizar sus derechos ciudadanos dentro y fuera del país.

* La formulación e implementación de políticas públicas -que incluyan de manera transversal la perspectiva de género- que apunten a soluciones efectivas, eficientes y oportunas ante la continua pauperización de las condiciones de vida de la población venezolana, a fin de minimizar el creciente y acelerado flujo migratorio.

* La desburocratización de los procesos de otorgamiento de documentos de identidad necesarios para la movilidad internacional legal de los ciudadanos venezolanos.

* La generación y publicación oportuna de estadísticas confiables en los diferentes ámbitos por parte del gobierno venezolano.

* La adopción de políticas de integración por parte de los países receptores, a fin de evitar la proliferación y consolidación de circuitos de exclusión e irregularidad de los migrantes venezolanos, lo que podría incrementar sus problemas políticos e institucionales internos.

* La implementación de iniciativas específicas por parte de las autoridades y entes de competencia en Venezuela, pero también de los países convertidos en destino ante la victimización de las mujeres y la población LGBTI, 
entre estas: el fortalecimiento de los procesos de prevención y atención de la violencia por razones de género, la sensibilización de las mujeres sobre los riesgos de la migración, así como, el seguimiento y monitoreo de estos crímenes, a fin de generar herramientas para su efectiva, eficiente y oportuna comprensión, prevención, atención y sanción.

* La transformación de las narrativas mediático-televisivas en lo que refiere el fenómeno de la migración, a fin de erradicar discursos prejuiciosos, estereotípicos y xenofóbicos que favorecen la ocurrencia de formas de discriminación, violencia, linchamientos y homicidios contra los migrantes venezolanos.

* La creación de redes entre la población venezolana migrante $y$ residente, $a$ fin de garantizar, facilitar y mantener el intercambio económico, informativo, tecnológico, cognitivo, cultural y afectivo.

\section{BIBLIOGRAFÍA}

- Efecto Cocuyo. (2018). Al menos 188 venezolanas rescatadas este año tras ser explotadas sexualmente en 8 países. (24 de noviembre). Recuperado de https://goo. gl/1JvoYD

- Álvarez, R. (2004). La dinámica migratoria colombo-venezolana: Evolución y perspectiva actual. Geoenseñanza. 9 (2), p. 191-202.

- Ávila, K. (2018a) A Venezuelan Exodus? North American Congress on Latin America (NACLA). Recuperado de https://goo.gl/ fHxJdr

- Ávila, K. (2018b). ¿Cómo analizar las actuales cifras delictivas en Venezuela? Amnistía Internacional Venezuela. Recuperado de en: https://goo.gl/GZpX7E

- Banco Mundial. (2018). Migración desde Venezuela a Colombia: Impactos y estrategia de respuesta en el corto y mediano plazo. Recuperado de https://goo.gl/jCFv5R

- Banca \& Negocios. (2018). Relación dinero efectivo/liquidez cae a un nuevo mínimo histórico. Recuperado de https://goo.gl/ AdejWZ

- Barrios, L. (2018). Los pies en el suelo. Efecto Cocuyo. Recuperado de https://goo. gl/4jgvhQ

- Bermúdez, Y., Arias, R., Albornoz, N., y Morffe, M. (2018). Informe Sobre la Movilidad Humana Venezolana. Realidades y Perspectivas de Quienes Emigran. (9 de abril al 6 de mayo de 2018). Recuperado de https://goo.gl/P5FrcU

- Caracol. (2018). Denuncian desintegración familiar por éxodo de venezolanos. Recuperado de https://goo.gl/F1JWys

- Caribe Afirmativo. (2018). Crisis humanitaria de venezolanos LGBT en el Caribe. Recuperado de https://goo.gl/ foVsJE

- Cendas Finanzas Digital. (2018). Canasta alimentaria familiar se ubicó en Bs.S 121.719,00, aumentando Bs.S 69.396,68, $132,6 \%$ con respecto al mes de octubre de 2018. Recuperado de https://goo.gl/ig3DvS

- CEPAL. (2018) Estudio Económico de América Latina y el Caribe 2018. Evolución de la inversión en América Latina y el Caribe: hechos estilizados, determinantes y desafíos de política. Recuperado de https://goo. gl/6SHbkq

- CNUR. (2018). La cifra de personas refugiadas y migrantes venezolanas alcanza los 3 millones. Recuperado de https://goo. gl/e3N1HG

- Dávila, L. (2001). Fronteras confusas: impactos sociales de la migración. En La 
migración internacional y el desarrollo en las Américas. CEPAL. Santiago de Chile, pp. 259-274.

- EFE. (2018). EEUU anuncia 48 millones de dólares para refugiados y migrantes venezolanos. Recuperado de https://goo. $\mathrm{gl} / \mathrm{b} 37 \mathrm{euc}$

- EFE. (2018). Sánchez confirma una millonaria ayuda de la UE a Latinoamérica por la crisis venezolana. Recuperado de https://goo.gl/RL4JPJ

- El Espectador. (2018). Informe de Medicina Legal reveló incremento de muertes de venezolanos en Colombia. Recuperado de https://goo.gl/CdUXN4

- El Impulso. (2018). Maduro aprueba "plan de recuperación" para atender crisis en servicios públicos. Recuperado de https:// goo.gl/5w19c7

- España, L. y Ponce, M. (2018). Encuesta sobre Condiciones de Vida en Venezuela. Recuperado de https://goo.gl/JZT2Hf

- FAO. (2018). Panorama de la seguridad alimentaria y nutricional en América Latina y el Caribe. Recuperado de https://goo.gl/xZNYYB

- Fefarven Globovisión. (2018). Desabastecimiento de medicinas alcanza el 85. Recuperado de https://goo.gl/EdPqBA

- FIP. (2018). Inseguridad, violencia y economías ilegales en las fronteras. Los desafíos del nuevo gobierno. Recuperado de https://goo.gl/XsRi9G

- FMI. (2009). Manual de balanza de pagos y posición de inversión internacional, sexta edición (BPM6). FMI, Washington, D. C.

- --- (2018a) Perspectivas Económicas: Las Américas - Una recuperación despareja. Recuperado de https://goo.gl/T2yAc4

- ---. (2018b). Perspectivas de la economía mundial. Recuperado de https://goo.gl/tHGFji

- Freitez, A. (2018). Encuesta sobre Condiciones de Vida Venezuela 2017 ENCOVI. Emigración. IIES-UCAB. Recuperado de https://goo.gl/WG4jZM

- Gómez, A. y Rengifo, F. (1999). Dinámica de la migración colombiana a Venezuela en las últimas décadas. En Ramírez, S. y Cadenas, J. (codos. y eds.) Colombia-Venezuela: Agenda común para el Siglo XXI. Tercer Mundo Editores. Bogotá, pp. 319-361.

- HRW. (2018). El éxodo venezolano. Urge una respuesta regional ante una crisis migratoria sin precedentes. Recuperado de https://goo.gl/crdn1B

- Lander, E. (2018) Venezuela: el fracaso del proceso bolivariano. En Correa, J., Uemura, J. y Siqueira, F. (eds.) El eclipse del progresismo. La izquierda latinoamericana e debate. Colectivo 660 y Editora Elefante. Sao Paulo.

- Migración Colombia. (2018). Todo lo que quiere saber sobre la migración venezolana $y$ no se lo han contado. Recuperado de https://goo.gl/6ZSCGQ

- Ministerio del Poder Popular para Relaciones Exteriores. (2018). Plan Vuelta a la Patria en cifras. Recuperado de https:// goo.gl/3RtWnC

- Naciones Unidas. (1999). Recomendaciones sobre estadísticas de las migraciones internacionales. Recuperado de https:// goo.gl/PZieoq

- Naciones Unidas. (2018). Situación de Venezuela: Retos de protección. Recuperado de https://goo.gl/Egpx1Y

- Noticias ONU. (2018). La OIM lanza un plan para ayudar a los migrantes venezolanos. Recuperado de https://goo.gl/N7NLzt

- Noticiero Digital. (2016). Tomás Páez: Casi 2 millones de venezolanos han emigrado en los últimos 17 años. Recuperado de https:// goo.gl/ZN6dr8

- OCHA. (2018). Latin America and The Caribbean. Stocks of Venezuelan population in the region. Recuperado de https://goo. $\mathrm{gl} / \mathrm{gPzbBD}$

- OCAH. (2018). América Latina y el Caribe, Panorama Humanitario Mensual. Recuperado de https://goo.gl/zQWzZx

- OCDE. (2013). The fiscal impact of immigration in OECD countries. En International 
Migration Outlook 2013. OCDE. Paris.

- OIM (2018a). Informe sobre las migraciones en el mundo 2018. Recuperado de https:// goo.gl/nyX5FG

- OIM (2018b). Migration trends in the Americas. Bolivarian Republic of Venezuela. Disponible en: https://goo.gl/JCDvn5

- OIM y Ministerio de Desarrollo Social del Gobierno de la Ciudad Autónoma de Buenos Aires. (2014). Las mujeres migrantes y la violencia de género. Aportes para la reflexión y la intervención. Recuperado de https:// goo.gl/aXoC7q

- OMEG. (2018). Caracterización de Personas que Realizan Actividades Sexuales Pagadas en Contextos de Prostitución en Bogotá 2017. Recuperado de https://goo.gl/BY9Fv3

- ONU. (2018). Venezuela cae dieciséis puestos en el Índice de Desarrollo Humano. Noticias ONU. Disponible en: https://goo.gl/6a4QBg

- Páez, T. (2015). La voz de la diáspora venezolana. Madrid: La Catarata
- Palacios, Y. (2016). Perspectiva de género en los fenómenos migratorios: estudio desde Europa y América Latina. Revista CES Derecho. 7 (2), 145-162.

- Pineda, E. (2018). Migración, trata y femicidio: Las mujeres venezolanas en el exterior. LaRed21. Recuperado de https:// goo.gl/qS4aBn

- PNUD. (2018). Índices e indicadores de desarrollo humano: actualización estadística de 2018. Anexo estadístico. Recuperado de https://goo.gl/D7gUXf

- Ramos, F. (2010). La inmigración en la administración de Pérez Jiménez (19521958). Revista Heurística, (13), 94-101.

- Reuters. (2018). Mujeres y niños migrantes de Venezuela están más expuestos a explotación sexual y laboral: expertos. Recuperado de https://goo.gl/dJv2Ra

- Sandell, R., Sorroza, A. y Olivié, I. (2001). Inmigración: ¿un desafío con oportunidades? Recuperado de https://goo.gl/6SX3GP 